\title{
Developing a Novel Mobile Banking Software Process Architecture by Deploying eTOM Framework
}

\author{
R. Nassiri \\ supervisor, Islamic Azad University, Central Tehran Branch, Tehran, Iran \\ N. Farzi \\ Student, Islamic Azad University, Central Tehran Branch, Tehran, Iran
}

\begin{abstract}
Nowadays, with the progress and influence of information technology in financial organizations, the major challenge is the ability to apply multiple knowledge and skills in an organizational process. Under such a perspective, the entity of bank should not be defined as a set of functional areas but a combination of complex processes that together can constitute the totality of the organization. The banks also require utilization and development of communication processes and customer service for successful development of end-to-end interactions. In this regard, the study of mobile banking processes in order to analyze the existing situation in this area and the recognition of its current position in banks is imperative using process architecture.

Given that the eTOM1 framework as a process-driven framework plays an important role in supporting interactions with users and customers and upgrading existing processes in the organization. Using the eTOM framework in business to customers (B2C) and the combination of those together to provide convenient services to users may be widely deployed in mobile banking. As a result, it's attempted that by investigating mobile banking systems and using an eTOM framework, new process architecture will be provided so that small steps could be taken to achieve the goals of banks i.e. the quality of services and products offered to customers and their satisfaction and loyalty rate.
\end{abstract}

Keywords: Mobile Banking, Enterprise Architecture, eTOM Framework

\section{INTRODUCTION}

Banking based on mobile is one of the recent achievements of IT at banking industry and it provides a number of tangible advantages for banks and their customers. Surviving in a tough competition environment, cost reduction, the chance of extensive communication, saving money and time, the existence of easiest accessibility while highest speed of providing services can be considered as a few of advantages for mobile banking. The pervasive use of mobile provides a chance for banks by presenting one of their electronic banking services not only for presenting new services, but also being attractive for customers by satisfying the needs and reducing their problems in comparison to traditional banking and thus may increase relaxation and satisfaction of customers.

\section{MOBILE BANKING}

Nowadays, services procured via mobile banking becomes a competitive advantage and each bank attempts to provide innovative and distinguished services via mobile devices in such way that one can consider a business model based on mobile for banks. Banks are now able to introduce various services to their customers in the domain of banking from few financial exchange-billing, request-command transfer money, sending prompt messages from bank to customer and etc. to different kinds of mobile banking based on short message, automatic payment via browser, mobile banking based on applicable programs. Mobile banking brings a number of advantages that among them we can refer to saving time for customer, operating at any place and nonstop, with high security while increasing use of telecom operators instead of Internet. Notwithstanding along with these advantages, mobile banking has some demerits such loss of mobile phone and access to users' information and limit cover of banks at presenting services and etc.[1,2,3,4,5,6]

\footnotetext{
${ }^{1}$ Enhanced Telecom Operation Map
} 


\section{THE ROLE OF ARCHITECTURE}

Where there is a clear need for entity designing and/or systematic designing that its complexity is beyond certain margin or may impose specific requirements, there is a need for specific design view that is called architecture[7].

\section{Service-Oriented Architecture at Banking}

In response to dynamic needs of customers, the bank has to generate new programs that may cause repetitive applications and interfaces, increasing problems of update, decrease of flexibility, lack of standards for unifying programs, increasing saving cost and increasing time of presenting services to markets. As a result, it becomes the need for change at structure and reuse of current properties of bank. A nominated key point in this respect is combination of business logic with the use of Service-Oriented Architecture and including features like identifying and managing business process, definition of business and services, functional programs, analyzing business process, defining required component and finally implementing and turning[8].

\section{Enterprise architecture}

Zackman defined enterprise architecture as a set of descriptive models in respect to anatomy of an organization, in such way that can match with management's needs and it keeps in the area of its useful life. The need for enterprise architecture can be distinguished at present state of major organization while the need for designing and developing complex information systems, existence of information system with the specific purpose and importance of flexibility of organization against external pressure like changing business, changing missions and organizational structure and prompt technological changes are major indicators. it consists of three key components as current architecture, desirable architecture and a transferring program. Advantages and reasons of using[9].

\section{eTOM Framework}

Many Models, frameworks and various standards for implementing, IT management and governing are introduced by companies like eTOM, ISO/IEC ${ }^{1} 20000$, ITIL ${ }^{2}$ and others. eTOM Framework is a guidance massive document that is counted as accepted standard of business process at communication industry domain and follows a customer-oriented pattern. eTOM framework looks down to enterprise process and it starts from general and then incorporates details and it divides into five levels that consist following cases[10,11,12]:

zero level: includes business activities that identify concentrated processes on customers from strategic and management process.

One level: includes categorize of processes that consist business performance and end-to-end standard processes.

Two level : it is key process (core process) that combine end-to-end processes for delivering services of progress.

Three level : this level includes tasks and steams of successful business processes model in detail form.

Four level : this level includes phases and detail operational processes along with stumble conditions and different kinds of geography and products.

Five level : this phase includes more analysis at operations and progress of related operational processes.

\footnotetext{
${ }^{1}$ International Organization for Standardization

2 IT Infrastructure Library
} 


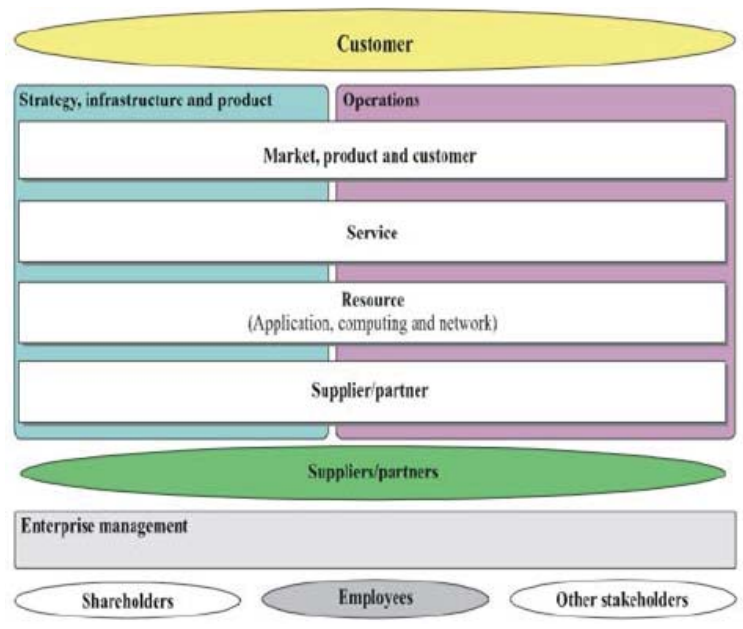

First level of eTOM framework

\section{BIAN1 Architecture}

Given to advance of banking services, banks require model for regressive the unify costs. Among these, BIAN is a model based on Service-Oriented Architecture (SOA) with definitions of fixed services and definition of levels and specified measure between services. The capacity that makes the chance of selecting and unifying various products from various organizations and cause controlling a particular business. The other purpose of it is conducting banking industry at creating public agreement to flexible architecture for putting response to business needs for subtractive costs that is the essential approach of bank in the field of using IT industry. The perspective of services at BIAN architecture includes building block and the elements of services that can be in a suitable set cooperate from one domain to other. There are various criteria for this classification that one of them is domain of servicing and include following items[13,14,15,16]:

- Business area : it is the highest level of attraction and includes business capacity, services, activities and requirements for specific information.

- Business domain : a coherence set of business capacity and services that are inter related to each other in this area and recognizing knowledge and skill of banking business.

- Services domain: it is the best level of classification and is known as a center of services and includes definition of unique business capacity and building block of elements.

- Service domain: includes groups of services and operation of related services. Each services scope devotes a particular area of business.

\section{DEVELOPING OUR PROPOSED ARCHITECTURE}

In designing architecture of proposed process, we rely on reference architecture. Reference architecture is what that provides the best practice of consistent structures and elements for getting purposes that grantees the chance of success in a reasonable time. Among current reference model, service based oriented architecture model with use of features and capacity like capacity of reuse, unique structure and presenting concise definition of required process, while clarifying borderlines between them, enable banks to increase capacity of reuse and consist complexity. In other hand for management of operation of systems and distance-based applications, exchanging structure of business to customer's needs, using service based architecture for developing services, while matching with eTOM, $\mathrm{SID}^{2}, \mathrm{TAM}^{3}$ frameworks, we use current network infrastructure and enhancement cooperation among IT network and business of organization in current effective services of Telecom ${ }^{4}$

\footnotetext{
${ }^{1}$ Banking Industry Architecture Network

2 Information Framework

${ }^{3}$ Telecom Application Map

${ }^{4}$ Telecom Reference Architecture
} 
model[17]. To fulfill those, proposed architecture is designed in five layers as, access channel layer, customer relationship management layer, common bus layer, services \& Operation Layer and network layer.

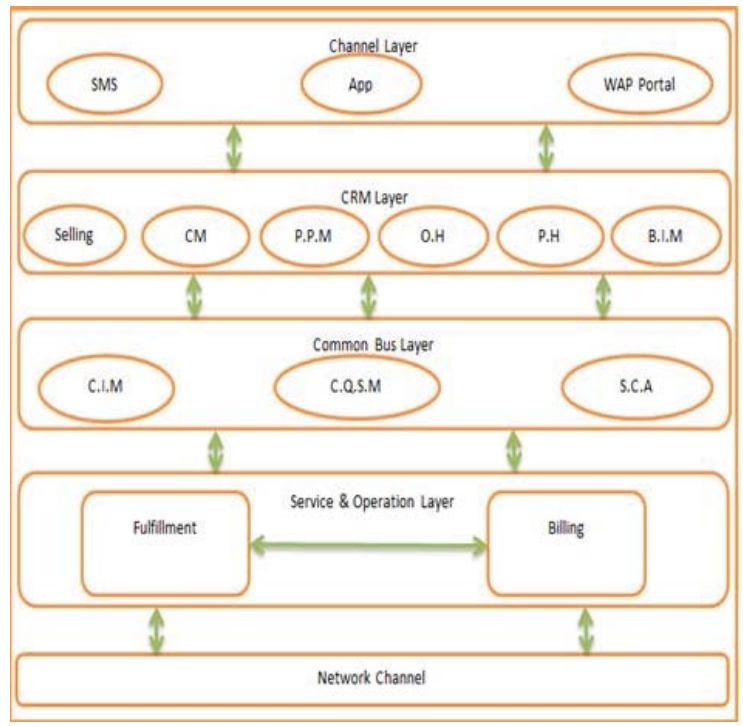

Developing architecture layer

These layers with the use of processes and sub-processes of second and third level of eTOM framework are defined as follow:

- The access channel layer: this layer is covered with market sales support and readiness and sub-process support selling. These processes are accessible for management of all channels' activities of sale and ensure that it has all capacities for processing and supporting these processes like sell for efficient export and marketing account.

$>$ Customer relationship management ${ }^{1}$ layer: this layer covered following processes :

- Sub-processes of selling are covered at the area of fulfillment that its purpose is potential customer management and matching expectations with products, services, the capacity presenting them to customers and management of correct response to them.

- Sub-processes of product performance management are covered at the area of processes of product, assurance that its purpose is functional management of products, supervision, analysis, improving and reporting particular products and continuous provision over provided parameters and ensure correct function.

- Sub-processes customer management are covered at the processes of customer and fulfillment that its purpose is managing communication with customer. This process at initial phases of cycle of customer starts and it continues after communicate with customers with organization and receiving a suitable response. This process of is the responsible of communication of management with customers, to sure that each customer has a unique identity and it also causes evaluating the cost of customers and assessing their satisfaction.

- Sub-processes order handing are covered in the customer and fulfillment processes that is responsible for receiving and publishing needs of customers. The purpose if it is management of all activities in respect to customers includes the possibility before order, assessing license, word-finding issue orders, updates and informing customer from current orders, publishing new demands, finishing previous demand and ensure that all activities are efficient and are presented in a suitable time.

- Sub-processes of problem handling are covered in the area of customer and assurance processes that is responsible of management of reports of problems by customers in respect to presented products and

${ }^{1} \mathrm{CRM}$ 
services. The aim of this process is to receive report of problems from customers, analyzing, solving, presenting fix and recognizing activities.

- Sub-processes of Bill Invoice Management are covered at the area of billing and revenue, customer and management that is responsible of management of making suitable bill. This process includes activities like setting, discount, loans. The aim of these processes is to sure that Invoice customers' bills are presented and generated on time.

- Common Bus layer: processes of this layer for realizing interests of customers regarding to acquired information are for presenting better services and matching products with the needs of customers that cause improving performance of organization, and increasing faith of customers. In other hand, the processes of layer cause increasing capacity of reuse and cooperation among components:

- Sub-processes customer information management are covered in the area of customer and fulfillment that is responsible of ensure of it that after each appeal of customer and completing if that and the information updates and it is at the services of other area of CRM and Services. The aim of these processes is to register customer's information, daily supporting, improving customer's experiment, supporting successful marketing and analyzing systems. These processes includes other sub processes in third level that include following items:

$\checkmark$ Create customer record for ensuring that each customer has a separate file for saving information and its activities

$\checkmark$ Update customer data for ensuring that data and customer information updates after each activity. This data includes selling and buying or managing request.

$\checkmark$ Notify customer data change for ensuring that other processes aware changes in data and information and if it is necessary they access it.

$\checkmark$ Build unified customer view for collecting and matching information of customers and business rules. This process updates after each activity or appeal of recovering information of customers.

- Sub-processes of customer SLA ${ }^{1}$ management are covered in the area of processes assurance and customer that is responsible, provision, and delivering the quality of products and services based on current contract, description of services or catalogue. The purpose of these products and functional parameters regarding to level of contracts and interest of customer-parameters of function of sources, managing bill and collecting this information. The other sub processes that are defined in third level are as follow:

$\checkmark$ Access customer QoS ${ }^{2}$ SLA performance for ensuring that all functional activities of management are evaluated and this function is based on demands of customers and products and sources at access.

$\checkmark \quad$ Manage QoS/SLA violation for ensuring that function of products and services with contracts of customers or services are not contradict of if contradict it will remove.

$\checkmark$ Report QoS/SLA performance informed reports of changes.

$\checkmark$ Track and management customer QoS/SLA performance resolution for follow up and managing processes of improving function and quality-cooperation-analysis-and restoration of products and also inform and reporting.

- Sub-processes and service configuration \& activation are covered in the area of fulfillment and services processes that is responsible of activation and services experiment from customers or other processes. The aim of these processes is preventing lack of access of resource facilities and product and service. These processes include confirmed activities and demands and devoting them and ensure that these activities will operate correctly the other sub processes will explained in third level and include following items:

$\checkmark \quad$ Allocate specific service parameters to services for devoting particular parameters to service. This devotion is done by possibility of appeal of orders or appeal of designing services processes and are accessible. Regarding to business rule, commitment of source at service level, processes and parameters related to reserve. In fact this process for possibility of required services for removing appeal and orders of customers.

$\checkmark \quad$ Track \& manage service provisioning for ensuring all matching activities, management and follow up services correctly. This process include activities include generating appeal of related source based on orders of services-increasing the situation of orders matching with business rule and essential commitment for implementing process and adding information to services and changing orders.

$\checkmark \quad$ Implement \& configure \& activate service for activating services at the time of order and appeal of services. This process include activities like evaluating of performance, performing reuse of

\footnotetext{
${ }^{1}$ Service Level Agreement

${ }^{2}$ Quality of Service
} 
implement of applicable standards, informing and warn about activities \& structure and wrong activation and updating current situation of information.

$\checkmark \quad$ Test services end-to-end for ensuring that all parameters of services activities regarding to function and quality of services correctly operate and are evaluated before presented to customer.

Presenting Service \& Operation Layer: the processes of this layer include two sections: billing and fulfillment:

- Fulfillment:

- Sub-processes service problem management are covered at the area of service and assurance that is responsible of managing problem at services. The aim of this process is responses to problem and presenting report to other processes and presenting substitute services for minimizing failure and its effect on customers.

- Sub-processes service quality management are covered in the area of processes of assurance and service that is responsible of management, provision, analysis, developing and presenting reports of function of services and products.

- Sub-processes resource provisioning are covered at the area of resource and fulfillment that is responsible of providing devote, installation, structure, activation, and experiment of required resources of services and response to other process. the aim of this process is avoiding the decreasing lack of capacity of resource, ensuring of accessibility of it and managing failure situation.

- Billing:

- Sub-processes of billing payment and receivable are covered at the area of processes billing and customer revenue management that is responsible of payments and customers' issue. The activities of this process include process and provision to current situation.

- Sub-processes of Bill inquiry handling are covered at the areas of billing and revenue customer and management that is responsible of effective consideration to all questions, problems and inquiry customers in respect to bill at the suitable time, management of interaction with customers in respect to bill and reports and updates them.

- Sub-processes manage billing events are covered at area of billing and revenue customer and management that is responsible of managing bills. Activities of this process include required function for conducting, distribution, collecting and analyzing bill. These processes may occur at real time or at particular time of performance. The document of events of bill will analyze by various elements related to products. These documents necessarily are used for response or editing with extra detail will at the access of customers.

\section{COMPARING COMMON BUS LAYER TO BIAN ARCHITECTURE}

At BIAN architecture the area of business services and sales are covered that its sub areas and its processes are ad follow:

- Sub-processes of customer agreement at section of customer management that its aim is to present regulations of selling products.

$\checkmark \quad$ This process is only refers to regulation of selling contract and it does not note agreement, interest, and demands and needs of customers. While at eTOM framework with regarding definition of process in the area of customer SLA management and processes and sub processes of customer information management interpret rules and standards at servicing level and cause unity and standardize services regard to needs of customers.

- Sub-processes of customer case management at servicing section that its aim is follow up and evaluating required activities and devoting sources and optimal function.

$\checkmark$ This process also refers to devoting sources and evaluating activities and there is no concise definition about access of source and devoting and evaluating presented products.

$\checkmark \quad$ In other hand these processes do not mention definition of structure and product and thus there is no solution for capacity of reuse product.

$\checkmark$ There isn't also a process for evaluating quality of product and services. If there is a concise process at eTOM framework, it is labelled at the area of customer management that it examines quality and services regarding to needs of customer and improving function and increasing faith of customers.

$\checkmark$ In eTOM framework with concise definition processes and sub processes at section service configuration and activation explain all banking industry activities and structure of reuse. 
Generally achieved results are presented at following table:

\begin{tabular}{|c|c|c|}
\hline Type & Framework eTOM & BIAN architecture \\
\hline Definition of contract of products & $\checkmark$ & $\sqrt{ }$ \\
\hline $\begin{array}{l}\text { Natching services function and } \\
\text { product with SLA contract }\end{array}$ & $\checkmark$ & \\
\hline Defining contract of customer & $\checkmark$ & $\sqrt{ }$ \\
\hline $\begin{array}{l}\text { Controlling quality of Qos and } \\
\text { products regarding to needs of } \\
\text { leamers }\end{array}$ & $\checkmark$ & - \\
\hline $\begin{array}{l}\text { Examining accessible source at } \\
\text { orgamization }\end{array}$ & $\checkmark$ & $\bar{v}$ \\
\hline $\begin{array}{l}\text { Deroting required source and } \\
\text { products }\end{array}$ & $\checkmark$ & - \\
\hline $\begin{array}{l}\text { Examining accessible services at } \\
\text { organization }\end{array}$ & $\sqrt{ }$ & - \\
\hline $\begin{array}{l}\text { Restructure services and products } \\
\text { regarding to needs of customers }\end{array}$ & $\checkmark$ & - \\
\hline Increasing the capacity of reuse & $\checkmark$ & - \\
\hline $\begin{array}{l}\text { Evaluating services function and } \\
\text { products }\end{array}$ & $\sqrt{ }$ & - \\
\hline
\end{tabular}

Comparative table of common channel layer BIAN architecture

\section{CONCLUSION}

We at proposed architecture by definition and deigning common bus channel layer, could achieve a wise and organized set of services. This is achieved by collecting information of customer relationship management layer and also analyzing the demands of customers while merged with information gathered from products and current resources. At the next step the quality of services may be evaluated by scrutinizing the ongoing contracts and regulations imposed. This outcome, in turn may reach to higher loyalty and customer satisfaction. This may also ends to a better forecasting of future needs and willingness of customers and getting a better market.

\section{REFERENCES}

[1] M. K. harma, and, R. Dubey, "Prospects of Technological Advancements in Banking Sector Using Mobile Banking and Position of India", International Association of Computer Science and Information Technology, Spring Conference, 2009.

[2] K.Kavitha, "Mobile Banking Supervising System- Issues, Challenges \& Suggestions to improve Mobile Banking Services", Advances in Computer Science: an International Journal, July, 2015.

[3] P. Nand, R. Astya, Anika, and, D. Singh, "An Add-on to Present Banking: m-banking", Springer, 2015.

[4] H. Lee, G. Harindranath, S. Oh, and, D.J. Kim, "Provision of Mobile Banking Services from an Actor-Network Perspective: Implications for Convergence and Standardization", Elsevier, March , 2014.

[5] R. Chandran, "Pros and Cons of Mobile Banking", International Journal of Scientific and Research Publications, October, 2014.

[6] R.S. Rao, "Trends, Challenges and Future Functionalities in Mobile Banking", International Journal of Research in Advent Technology, December, 2013.

[7] S. Bhosale, and, M. Bhosale, "Architectural considerations while developing Enterprise Mobile Applications', International Journal of Scientific and Research Publications, March, 2014.

[8] C.K.Gomathy, and, S.Rajalakshmi, "A Software Design Pattern for Bank Service-Oriented Architecture", International Journal of Advanced Research in Computer Engineering \& Technology, April, 2014.

[9] C. F. Lukhele, E. K. Ngassam, and, I. Osunmakinde, "A Framework for Measuring the Value of Enterprise Architecture in South African Telecommunications Organizations", Institute for Computer Sciences, Social Informatics and Telecommunications Engineering, 2015.

[10] TMForum advisory Group, "Business Process Framework (eTOM) Primer”, TM Forum, April, 2015.

[11] TMForum advisory Group, "Business Process Framework (eTOM) Poster Frameworx", TM Forum, April, 2015.

[12] B. Raouyane, M.Errais, M.Bellafkih, and, M. Ramdani, "IMS Management \& Monitoring with eTOM framework And composite web service", International Conference on Multimedia Information Networking and Security, 2010.

[13] D. Lee, S. Kumaran, and, P. Patnaik, "Advances in Banking Transformation using BIAN and IBM Industry Models", Advances in Banking Transformation using BIAN and IBM Industry Models, 2014.

[14] G. Rackham, "BIAN How-to Guide- Applying the BIAN Standard", BIAN Homepage, March, 2015. 
[15] G. Rackham, "BIAN How-to Guide Developing Content", BIAN Homepage, March, 2015.

[16] L. Zhang, Y. Wang, and, F.j. Li, "The Banking System Reference Implementation Based on SOA”, Fourth International Joint Conference on Computational Sciences and Optimization, 2011.

[17] G. K. Behara, P. Mahajani and, P. Palli, “Telecom Reference Architecture”, TM Forum, September, 2010. 